\title{
Valve-related complications after mechanical heart valve implantation
}

\author{
Yoshio Misawa
}

Received: 17 September 2014 / Accepted: 24 October 2014 / Published online: 18 December 2014

(C) The Author(s) 2014. This article is published with open access at Springerlink.com

\begin{abstract}
The number of heart valve surgeries is increasing, and 19,164 patients underwent heart valve surgery in Japan in 2011. The early mortality rate has remained stable for more than 10 years. Many patients now survive for many years, with a reported 10-year survival rate of at least $60 \%$. However, unfavorable complications can occur after valve surgery. Valve-related complications include thromboembolisms, bleeding complications and prosthetic valve endocarditis, followed by structural and nonstructural prosthetic valve dysfunctions. Our review of studies published after 2000 revealed that the rate of all valve-related complications was $0.7-3.5 \%$ per patient-year. Thromboembolisms occur at a rate of approximately $1 \%$ per patientyear, and bleeding complications occur at almost $0.5 \%$ per patient-year. Thromboembolic and hemorrhagic events related to anticoagulant therapy should be considered during life-long follow-up. The occurrence rate of endocarditis reaches $0.5 \%$ per patient-year, with a poor postoperative survival. Structural dysfunctions have been largely overcome, and the nonstructural dysfunction rate is $0.4-1.2 \%$ per patient-year. The nonstructural dysfunctions induced by paravalvular leaks and pannus ingrowth are also issues that need to be resolved.
\end{abstract}

Keywords Valve-related complication - Mechanical heart valve $\cdot$ Heart valve replacement $\cdot$ Heart valve surgery

Y. Misawa $(\bowtie)$

Division of Cardiovascular Surgery, Jichi Medical University, 3311-1 Yakushiji, Shimotsuke, Tochigi 329-0498, Japan e-mail: tcvmisa@jichi.ac.jp

\section{Introduction}

In 2011, 19,164 patients underwent heart valve surgery in Japan, and the postoperative early death rate was $3.4 \%$ [1]. The number of heart valve surgeries is increasing, and the early mortality rate has remained stable for more than 10 years [2]. Tissue valves are more likely to be implanted than mechanical ones in Japan, with 9,832 tissue and 5,452 mechanical heart valves implanted in 2011. The prolonged durability of the tissue valves, an aging population and the expansion of plastic surgery techniques have all decreased mechanical valve use. However, mechanical valves appear to be a better option for some patients. We choose a mechanical valve for young adults and patients with endstage renal disease because of the more rapid onset of structural dysfunction of tissue valves [3].

Many patients now survive for many years after valve implantation, with a reported 10-year survival rate of at least $60 \%$ [4-7]. However, unfavorable complications can occur after valve surgery. We herein review and discuss mechanical prosthetic valve-related complications.

\section{All valve-related complications}

Edmunds et al. [8] designed the guidelines for reporting outcomes after prosthetic valve replacement, and many articles have been published based on these guidelines. The authors stated that the valve-related complications include thromboembolisms, bleeding complications and prosthetic valve endocarditis, followed by structural and nonstructural prosthetic valve dysfunctions. Our review of studies published after 2000 revealed a rate of valve-related complications of $0.7-3.5 \%$ per patient-year [2, 8-14]. The occurrence rates of individual complications and references are shown in Table 1. 
Table 1 The occurrence rates of complications and references

\begin{tabular}{llllll}
\hline & All valve-related complications & Thromboembolism & Bleeding & Endocarditis & Nonstructural dysfunction \\
\hline \% per patient-year & $0.7-3.5$ & Approximately 1.0 & $<0.5$ & $<0.5$ & $0.4-1.2$ \\
References & {$[2,8-14]$} & {$[5,9,10,15-19]$} & {$[5,15,16]$} & {$[10,21-25]$} & {$[9,39-57]$} \\
\hline
\end{tabular}

\section{Thromboembolism and bleeding complications}

Thromboembolisms, such as cerebral infarction and prosthetic valve thrombosis, and bleeding complications might be related to the use of warfarin anticoagulation therapy. Other reasons include intrinsic coagulation factors, intestinal lesions, atrial enlargement, arrhythmias such as atrial fibrillation and other causes. A preoperative history of cerebrovascular events is also a risk factor for thromboembolic or bleeding complications $[5,15,16]$. Thromboembolisms occur at a rate of approximately $1 \%$ per patient-year, and bleeding complications at almost $0.5 \%$ per patient-year.

The 2014 American Heart Association/American College of Cardiology guidelines for the management of patients with valvular heart disease state that an international normalized ratio (INR) of 2.5 is recommended in patients with a mechanical valve at the aortic position, and an INR of 3.0 should be obtained for those with a valve implanted at the mitral position [17]. Therapy with 75-100 mg aspirin daily is also recommended. Some authors recommend an INR of 2.6-3.0 for aortic valve replacement patients and 3.0-3.5 for mitral valve replacement patients $[9,10]$. The Japanese guideline published in 2012, however, recommended a slightly lower INR between 2.0 and 3.0 [18]. Our present INR target value is between 1.8 and 3.0 for all patients, with additional dipyridamole or aspirin administration [4]. For patients with atrial fibrillation and young patients, our criterion is based on the same recommendation, but for older patients with risk factors for cerebral bleeding, our target INR is below this recommendation.

A thrombosed prosthetic valve is an uncommon complication, but it is associated with high mortality and morbidity rates. In a literature survey of the clinical outcomes of patients with obstructive thrombosed prosthetic heart valves, Huang et al. [19] concluded that thrombolytic therapy was easier than surgery, with a recurrence rate of $13 \%$, while surgery was necessary in the $30 \%$ of cases with failure of thrombolytic therapy, and was associated with a mortality rate of at least $12 \%$.

\section{Endocarditis}

Prosthetic valve endocarditis requires complicated surgical procedures $[10,20]$ and sometimes leads to lethal clinical results, particularly in early-onset patients [21-25]. The occurrence rate of endocarditis is approximately $0.5 \%$ per patient-year. In 1996, Lytle et al. [21] showed that $13 \%$ of 146 patients had in-hospital deaths, and in 2014, Grubitzsch et al. [22] showed that the surgical mortality was $12.8 \%$ among 149 consecutive patients with prosthetic valve endocarditis. Therefore, the surgical risk of prosthetic heart valve endocarditis remains high, and Staphylococcal species are the most common causative organisms [20,21].

The postoperative survival in endocarditis patients is poor. Lytle and colleagues indicated that additional surgery was required in 19 of their patients, with a $60 \%$ survival rate at 10 years among the 127 hospital survivors [2, 4]. Grubitzsch et al. [22] recorded 69 early and late complications, including 35 deaths, 23 recurrences and 11 reoperations among 121 patients with a mean follow-up of 4 years.

\section{Structural dysfunction}

Structural dysfunction in first-generation and initial mechanical valves, such as the Starr-Edwards ball and Björk-Shiley valves, have been reported, although the long-term clinical results of both valves have been excellent [26-32]. The main causes of Starr-Edwards ball valve dysfunction have been ball fracture and cloth wear and tear, leading to valve regurgitation $[33,34]$. Björk-Shiley valve dysfunctions include leaflet dislodging and fracture.

These rare complications are typically observed more than three or four decades after implantation. Gunn et al. [31] concluded that the Björk-Shiley valve conferred excellent 30-year survival, was associated with three strut fractures during long-term follow-up, with a freedom from reoperation rate of $91 \%$ at 30 years. Harrison et al. [32] discussed 663 catastrophic failures of the valve among approximately 86,000 patients, and we reported a case of extraction of a worn Björk-Shiley prosthetic valve after 39 years because of the potential risk of structural valve dysfunction $[35,36]$. The implanted valve was functioning well in our case, but we identified the worn disc during aortic surgery for an acute aortic dissection. Björk pointed out the potential risk of disc wear and fracture, and the Björk-Shiley valve may be changed to pyrolytic carbon discs [37].

As mentioned above, the structural dysfunction of mechanical valves has been largely resolved, 
including leaflet dislodging and disc fracture and the current mechanical valves show an extremely low occurrence rate of structural valve dysfunction. Structural dysfunction among major commercially available mechanical valves cannot be recognized, even in children [4-7]. Currently, structural dysfunction remains an issue with tissue valves.

In 2008, Cianciulli et al. [38] reported a case of structural dysfunction in a mechanical prosthetic valve made by Tri-technologies Inc., which is a made-to order manufacturer that produces vales for sale to private customers. This case is a specific example, and not the norm.

\section{Nonstructural dysfunction}

Nonstructural valve dysfunction includes paravalvular leaks without apparent endocarditis, cusp entrapment by a pannus or other causes. Clinically important hemolytic anemia can occur with a lower incidence than these complications [39].

Before the publication of guidelines for a linearized rate for reporting outcomes after prosthetic valve replacement, investigators did not report nonstructural dysfunction systematically. The nonstructural dysfunction rate reported by Edmunds and colleagues was $0.4-1.2 \%$ per patient-year among recent mechanical heart valves [40-43].

Paravalvular leaks without apparent endocarditis and pannus formation often lead to reoperation, and are caused by technical errors, latent prosthetic endocarditis or annular calcification. A minor leak might be subclinical in the aortic position, but hemolysis caused by the leak can lead to reoperation in the mitral position. Akins et al. [44] reported the clinical results of 136 consecutive patients with paravalvular leaks, and primarily repaired or replaced the implanted valves. We reported a case that presented with hemolysis 5 years after a third mitral valve operation [45]. The intraoperative findings revealed severe calcification around the regurgitant orifice, and we successfully repaired the valve primarily. We inferred that the hard calcification and the prosthetic valve ring wore the tissue around the prosthesis. Technical errors should be overcome, and improved histocompatibility of the suture ring of the mechanical valves may also help avoid this complication.

Pannus formation might prevent a leaflet from functioning well, and the presence of a pannus on the outflow of the left ventricle below a mechanical valve could narrow the outflow orifice, causing stenosis. This complication occurs mainly after long procedures. We reported a case with a pannus, in which the pannus was resected using rotatable tilting disc prosthesis, resulting in successful preservation of the intact prosthesis [46]. We also experienced four other reoperation cases due to pannus formation [47, 48]. The earliest case received reoperation at 97 months, and the other three cases were treated between 20 and 39 years after the initial operations. Oh et al. [49] reported a large amount of pannus ingrowth in 33 aortic valve replacement patients with an increased mean pressure gradient. The mean interval from the previous operation was $16.7 \pm 4.3$ years, and the authors showed that the most common etiology for the previous surgery was rheumatic valve disease. Ellensen et al. [50] also reported a large series of 27 cases, and showed that females and younger patients had a higher risk of pannus formation. Al-Alao et al. [51] reported a rare case with pannus formation 3 months after surgery. Certain intrinsic factors might contribute to pannus formation, and manufacturers have been changing their designs and suture ring fabric compositions to prevent a pannus from developing. The results of these changes will take several decades to become evident.

In addition, diagnosing pannus formation is not easy. The clinical signs of implanted valve dysfunction, such as stenosis, might indicate certain diagnostic procedures, and an echocardiogram is the key to detect valve dysfunction. However, Xu et al. [52] showed that fluoroscopic examination was useful to reveal a radio-opaque ring within the implanted valve orifice, and Teshima et al. [53] studied the effectiveness of multidetector-row-computed tomography to demonstrate pannus overgrowth on the inflow aspect of the prosthetic valve.

Some authors found an annular valve suture interfering with the normal closure mechanism of a prosthetic leaflet, causing valve dysfunction $[54,55]$. The normal prosthetic valve function was restored after removing the suture material. Apparent hemolysis without a paravalvular leak has been rarely reported [9, 56, 57]. Borman et al. [57] showed that simultaneous aortic and mitral valve replacement caused relatively increased hemolysis compared with single valve replacements, and indicated that all of six instances treated at their institution did not require reoperation.

\section{Conclusions}

Valve-related complications after heart valve replacement with mechanical valves occur at acceptable rates. The structural dysfunction has been largely overcome; however, prosthetic valve endocarditis may still result in death. Thromboembolic and hemorrhagic events related to anticoagulant therapy should be considered during life-long follow-up. Nonstructural prosthetic valve dysfunctions, such as paravalvular leaks and pannus ingrowth, are also issues that need to be resolved. 
Conflict of interest The author serves as a consultant for Terumo Co.

Open Access This article is distributed under the terms of the Creative Commons Attribution License which permits any use, distribution, and reproduction in any medium, provided the original author(s) and the source are credited

\section{References}

1. Amano J, Kuwano H, Yokomise H. Thoracic and cardiovascular surgery in Japan during 2011. Annual report by The Japanese Association for Thoracic Surgery. Gen Thorac Cardiovasc Surg. 2013;61:578-607.

2. Taniguchi S, Hashizume K, Ariyoshi T, Hisara Y, Tanigawa K, Miura T, Odate T, Matsukuma S, Nakaji S, Eishi K. Twelve years of experience with the ATS mechanical heart valve prostheses. Gen Thorac Cardiovasc Surg. 2012;61:561-8.

3. Misawa Y. Heart valve replacement for patients with endstage renal disease in Japan. Ann Thorac Cardiovasc Surg. 2010;16:4-8

4. Misawa Y, Saito T, Konishi H, Ohki S, Kaminishi Y, Sakano Y, Morita H, Aizawa K. Clinical experience with the Bicarbon heart valve prosthesis. J Cardiothorac Surg. 2007;25(2):8.

5. Misawa Y, Fuse K, Saito T, Konishi H, Oki S. Fourteen year experience of the Omnicarbon prosthetic heart valve. ASAIO J. 2001;47:677-83.

6. Aoyagi S, Oryoji A, Nishi Y, Tanaka K, Kosuga K, Oishi K. Long-term results of valve replacement with the St. Jude Medical valve. J Thorac Cardiovasc Surg. 1994;108:1021-9.

7. Shanmugam G, MacArthur K, Pollock J. Mechanical aortic valve replacement: long-term outcomes in children. J Heart Valve Dis. 2005;14:166-71.

8. Edmunds LH, Clark RE, Cohn LH, Grunkemeier GL, Miller DC, Weisel RD. Guideline for reporting morbidity and mortality after cardiac valvular operations. Ann Thorac Surg. 1996;62:932-5.

9. Azamoush K, Laborde F, de Riberolles C. The Sorin Bicarbon over 15 years clinical outcomes: multicenter experience in 1704 patients. Eur J Cardiovasc Surg. 2010;38:759-66.

10. Van Nooten G, Bové T, Van Belleghem Y, François K, Caes F, Vandenplas G, De Pauw M, Taeymans Y. Twenty-year singlecenter experience with the Medtronic open pivot mechanical heart valve. Ann Thorac Surg. 2014;97:1306-13.

11. Sezai A, Hata M, Niino T, Yoshitake I, Kasamaki Y, Hirayama A, Minami K. Fifteen years of experience with ATS mechanical heart valve prostheses. J Thorac Cardiovasc Surg. 2010;139:1494-500.

12. Baykut D, Grize L, Schindler C, Keil AS, Bernet F, Zerkowski HR. Eleven-year single-center experience with the ATS open pivot bileaflet heart valve. Ann Thorac Surg. 2006;82:847-52.

13. Spillopolos K, Haschemi A, Parasiris P, Kemkes BM. Sorin Bicarbon bileaflet valve: a 9.8-year experience. Clinical performance of the prosthesis after heart valve replacement in 587 patients. Inteact Cardiovasc Thorac Surg. 2009;8:252-9.

14. Borman JB, De Riberolles C. Sorin Bicarbon bileaflet valve: a 10-year experience. Eur J Cardiothorac Surg. 2003;23:86-92.

15. Labaf A, Grzymala-Lubanski B, Stagmo M, Lövdahl S, Wieloch M, Själander A, Svensson PJ. Thromboembolism, major bleeding and mortality in patients with mechanical heart valve-a population-based cohort study. Thromb Res. 2014;134:354-9.

16. Bourguignon T, Bergöend E, Mirza A, Ayegnon G, Neville P, Aupart MR, Marchand M. Risk factors for valve-related complications after mechanical heart valve replacement in 505 patients with long-term follow up. J Heart Valve Dis. $2011 ; 20: 673-80$.

17. Nishimura RA, Otto CM, Bonow RO, Carabello BA, Erwin JP III, Guyton RA, O'Gara PT, Ruiz CE, Skubas NJ, Sorajja P. 2014 AHA/ACC guideline for the management of patients with valvular heart disease: executive summary: a report of the American College of Cardiology/American Heart Association task force on practice guidelines. J Am Coll Cardiol. 2014;63:2438-88.

18. Ookita Y, Okada Y, Otsuji Y, Komeda M, Nakatani S, Matsuzaki M, Yoshida K (2012) Guidelines for surgical and interventional treatment of vascular heart disease (JCS). http://www.j-circ.or.jp/ guideline/pdf/JCS2012_ookita_d.pdf. Accessed 20 Oct 2014.

19. Huang G, Schaff HV, Sundt TM, Rashimtoola SH. Treatment of obstructive thrombosed prosthetic heart valve. J Am Coll Cardiol. 2013;62:1731-6.

20. Ramlawi B, White LE, Santora RJ, Reardon MJ. Recurrent prosthetic valve endocarditis with aortic-ventricular disruption: a surgical challenge. J Heart Valve Dis. 2013;22:126-33.

21. Lytle BW, Priest BP, Taylor PC, Loop FD, Sapp SK, Stewart RW, McCarthy PM, Muehrcke D, Cosgrove DM. Surgical treatment of prosthetic valve endocarditis. J Thorac Cardiovasc Surg. 1996;111:198-207.

22. Grubitzsch H, Schaefer A, Melzer C, Wernecke KD, Gabbieri D, Konertz W. Outcome after surgery for prosthetic valve endocarditis and the impact of preoperative treatment. J Thorac Cardiovasc Surg. 2014. doi:10.1016/j.jtcvs.2014.05.025.

23. Lalani T, Chu VH, Park LP, Cecchi E, Corey GR, Durante-Mangoni E, Fowler VG, Gordon D, Grossi P, Hannan M, Hoen B, Muñoz P, Rizk H, Kanj SS, Selton-Suty C, Sexton DJ, Spelman D, Ravasio V, Tripodi MF, Wang A. In-hospital and 1-year mortality in patients undergoing early surgery for prosthetic valve endocarditis. JAMA Intern Med. 2013;173:1495-504.

24. Nonaka M, Kusuhara T, An K, Nakatsuka D, Sekine Y, Iwakura A, Yamanaka K. Comparison between early and late prosthetic valve endocarditis: clinical characteristics and outcomes. J Heart Valve Dis. 2013;22:567-74.

25. Chirillo F, Scotton P, Rocco F, Rigoli R, Pedrocco A, Martire P, Daniotti A, Minniti G, Polesel E, Olivari Z. Management strategies and outcome for prosthetic valve endocarditis. Am J Cardiol. 2013;112:1177-81.

26. Björk VO. Disc wear in the Björk-Shiley tilting disc valve. Experiment and clinical observation. Scand J Thorac Cardiovasc Surg. 1971;5:87-91.

27. Björk VO. The pyrolytic carbon occluder for the Björk-Shiley disc valve prosthesis. Scand J Thorac Cardiovasc Surg. 1972;6:109-13.

28. Larmi TK, Kärkölä P. Shrinkage and degradation of Delrin occlude in the tilting disc valve. J Thorac Cardiovasc Surg. 1974;68:66-9.

29. Masumoto H, Shimamoto M, Yamazaki F, Nakai M, Fujita S, Miura Y. A case report of valve dysfunction. A case report of valve dysfunction associated with abrasion of Delrin disk used in early Björk-Shiley mitral valves requiring resurgery. Ann Thorac Cardiovasc Surg. 2009;15:126-8.

30. Motoki T, Matsueda T, Kurushima A, Otani T, Fukumura Y. Prosthetic valve dysfunction resulting from a Björk-Shiley Delrin disc fracture in the mitral position: a case report. Tokushima Red Cross Hosp Med J. 2013;18:36-9.

31. Gunn JM, Malmberg M, Vähäsilta T, Lahti AL, Kuttila KT. Thirty-year results after implantation of the Björk-Shiley convexo-concave heart valve prosthesis. Ann Thorac Surg. 2014;97:552-6.

32. Harrison DC, Ibrahim MA, Weyman AE, Kuller LH, Blot WJ, Miller DE. The Björk-Shiley convexo-concave heart valve 
experience from the perspective of the supervisory panel. Am J Cardiol. 2013;112:1921-31.

33. Shiono M, Sezai Y, Sezai A, Hata M, Iida M, Negishi N. Longterm results of the cloth-covered Starr-Edwards ball valve. Ann Thorac Surg. 2005;80:204-9.

34. Mazzucco A, Luciani GB, Pessotto R, Piccin C, Faggian G, Chiominto B. Ball fracture with the 6120-model Starr-Edwards mitral valve prosthesis occurring late after implantation. J Heart Valve Dis. 1993;2:245-7.

35. Komi M, Sugaya A, Akutsu H, Sato H, Kaminishi Y, Misawa Y. A worn Björk-Shiley prosthetic valve without dysfunction observed during ascending aortic replacement. Clinical Case Reports. 2014;2:180-2.

36. Björk VO. Disc wear in the Björk-Shiley tilting disc valve. Experiment and clinical observation. Scand J Thorac Cardiovasc Surg. 1971;5:87-91.

37. Björk VO. The pyrolytic carbon occluder for the Björk-Shiley disc valve prosthesis. Scand J Thorac Cardiovasc Surg. 1972;6:109-13.

38. Cianciulli TF, Lax JA, Saccheri MC, Guidoin R, Salvado CM, Fernández AJ, Prezioso HA. Retrieval of a leaflet escaped in a Tri-technologies bileaflet mechanical prosthetic valve. Eur J Echocardiogr. 2008;9:65-8.

39. Hurle A, Abad C, Feijoo J, Ray V, Ponce G. Long-term clinical performance of Sorin tilting-disc mechanical prostheses in the mitral and aortic position. J Cardiovasc Surg (Torino). 1997;38:507-12.

40. Cellento M, Filaferro L, Milano AD, Anastasio G, Ferrari G, Bortolotti U. Single center experience with the Sorin Bicarbon prosthesis: a 17-year clinical follow-up. J Thorac Cardiovasc Surg. 2013. doi:10.1016/j.jtcvs.2013.11.015.

41. Nishida T, Sonoda H, Oishi Y, Tanoue Y, Nakashima A, Shiokawa Y, Tominaga R. Single-institution, 22-year, follow-up of 786 CarboMedics mechanical valves used for both primary surgery and reoperation. J Thorac Cardiovasc Surg. 2014;147:1493-8.

42. Rezulli A, Ismeno G, Bellitti R, Casale D, Festa M, Nappi GA, Cotrufo M. Long-term results of heart valve replacement with bileaflet prostheses. J Cardiovasc Surg (Torino). 1997;38:241-7.

43. Bernet FH, Baykut D, Grize L, Zerkowski HR. Single-center outcome analysis of 1,161 patients with St. Jude medical and ATS open pivot mechanical heart valves. J Heart Valve Dis. 2007;16:151-8.

44. Akins CW, Bitondo JM, Hilgenberg AD, Vlahakes GJ, Madsen JC, MacGillivray TE. Early and late results of the surgical correction of cardiac prosthetic paravalvular leaks. J Heart Valve Dis. 2005;14:792-9.

45. Aizawa K, Tateishi A, Sakano Y, Kaminishi Y, Ohki S, Saito T, Konishi H, Kawada M, Misawa Y. Repair of paravalvular leak after third mitral valve replacement. Kyobu Geka. 2007;60:903-5.
46. Misawa Y, Fuse K, Kato M. Pannus resection through the tilting disc prosthesis: successful treatment preserving the prosthesis. Artif Org. 1997;21:1301-2.

47. Misawa Y, Saito T, Konishi H, Oki S, Kaminishi Y, Aizawa K, Takahashi H, Kamisawa O, Kato M, Fuse K. When and how does mechanical prosthetic heart valve dysfunction appear? Jpn J Thorac Cardiovasc Surg. 2003;51:355-60.

48. Misawa S, Aizawa K, Kaminishi Y, Muraoka A, Misawa Y. StarrEdwards valves at the aortic and mitral positions implanted for 39 years. Gen Thorac Cardiovasc Surg. 2011;59:433-5.

49. Oh SJ, Park S, Kim JS, Kim KH, Kim KB, Ahn H. Reoperation for non-structural valvular dysfunction caused by pannus ingrowth in aortic valve prosthesis. J Heart Valve Dis. 2013;22:591-8.

50. Ellensen VS, Andersen KS, Vitale N, Davidsen ES, Segadal L, Haaverstad R. Acute obstruction by pannus in patients with aortic medtronic-hall valves: 30 years of experience. Ann Thorac Surg. 2013;96:2123-8

51. Al-Alao B, Simonjul U, Heron B, Parissis H. Rapid pannus formation after few months of obstructing aortic mechanical prosthesis. Gen Thorac Cardiovasc Surg 2013 Sep 25. Epub ahead of print.

52. Xu B, La Gerche A, Nixon I, Maclsaac A. Fluoloscopic ring of pannus within a mechanical mitral valve: a novel sign of calcified pannus infiltration. Heart Lung Circ. 2014. doi:10.1016/j. hlc.2014.06.002.

53. Teshima H, Aoyagi S, Hayashida N, Shojima T, Takagi K, Arinaga K, Yoshikawa K. Dysfunction of an ATS valve in the aortic position: the first reported case caused by pannus formation. $\mathrm{J}$ Artif Organs. 2005;8:270-3.

54. Kidher ES, Perera R, Rao C, Rehman SM, Sutaria N, Athanasiou T. A rare case of suture material obstructing the closure mechanism of a prosthetic aortic valve: a case report. Cases J. 2009;2(2):9126. doi:10.1186/1757-1626-2-9126.

55. Ozakan M, Astarcioglu MA, Karakoyun S, Balkanay M. Extrinsic mechanism obstructing the opening of a prosthetic mitral valve: an unusual case of suture entrapment. Echocardiography. 2012;29:E28-9.

56. Nakano K, Koyanagi H, Hashimoto A, Kitamura M, Endo M, Nagashima M, Tokunaga $H$. Twelve years' experience with the St. Jude Medical valve prosthesis. Ann Thorac Surg. 1994;57:697-703.

57. Borman JB, De Riberolles C. Sorin Bicarbon bileaflet valve: a 10-year experience. Eur J Cardiothorac Surg. 2003;23:86-92. 